\title{
Association of Childhood Metabolic Syndrome and Metabolic Phenotypes with the Carotid Intima-Media Thickness (CIMT) in Early Adulthood: Tehran Lipid and Glucose Study
}

\author{
Majid Valizadeh \\ Research Institute for Endocrine Sciences \\ Erfan Tasdighi \\ Research Institute for Endocrine Sciences \\ Maryam Barzin \\ Research Institute for Endocrine Sciences

\section{Ramyar Hariri} \\ Research Institute for Endocrine Sciences

\section{Maryam Mahdavi} \\ Research Institute for Endocrine Sciences \\ Pooneh Dehghan \\ Taleghani hospital \\ Amin Momeni Moghaddam \\ Taleghani hospital \\ Fereidoun Azizi \\ Research Institute for Endocrine Sciences
}

Farhad Hosseinpanah ( $\nabla$ fhospanah@endocrine.ac.ir)

Research Institute for Endocrine Sciences

\section{Research}

Keywords: Obesity, Metabolic syndrome, Adolescence, Carotid intima-media thickness, Atherosclerosis

Posted Date: August 31st, 2021

DOI: https://doi.org/10.21203/rs.3.rs-836884/v1

License: (1) This work is licensed under a Creative Commons Attribution 4.0 International License. Read Full License

Version of Record: A version of this preprint was published at International Journal of Cardiology on December 1st, 2021. See the published version at https://doi.org/10.1016/j.ijcard.2021.12.010. 


\section{Abstract}

Background: The prevalence of metabolic syndrome (MetS) during adolescence has shown an increasing trend. This study aimed to investigate the association of MetS and metabolic phenotypes with a high carotid intima-media thickness (CIMT) in early adulthood in the framework of a large cohort study.

Methods: MetS was defined as proposed by Cook, de Ferranti, the National Cholesterol Education Program (NCEP), and the pediatric International Diabetes Federation (IDF). Metabolic phenotypes were defined based on the binary clustering of cardiovascular risk factors. The participants were followed up for 18.2 years. Multivariate-adjusted odds ratios (ORs) were calculated for a high CIMT incidence ( $\geq 95^{\text {th }}$ percentile).

Results: In this study, 862 adolescents (52.3\% males), with the mean age of $13.4 \pm 2.2$ years, were included. The presence of MetS, based on the definitions proposed by Cook (OR=1.90, 95\% Cl: 1.01-3.57, $\mathrm{P}=0.046)$ and de Ferranti $(\mathrm{OR}=1.74 ; 95 \% \mathrm{Cl}$ : 1.04-2.90, $\mathrm{P}=0.033$ ), was associated with the increased risk of a high CIMT in early adulthood. Metabolic phenotypes, including high waist circumference (WC)/hypertension (HTN), high WC/low high-density lipoprotein-cholesterol (HDL-C), and high triglyceride (TG)/high WC, showed higher risks of a high CIMT. However, these positive associations become insignificant after adjusting for the adulthood BMI, except for the high WC/low HDL-C phenotype (OR=2.04, 95\% Cl: 1.02-4.11, P=0.044).

Conclusion: The high WC/low HDL-C phenotype had a better predictive value and could be used as a simpler alternative for MetS to identify adolescents with a higher risk of high CIMT during early adulthood.

\section{Introduction}

Metabolic syndrome (MetS) is a complex disorder, defined by a cluster of interrelated criteria, including dyslipidemia, elevated blood pressure, and dysregulated glucose homeostasis, with abdominal obesity and/or insulin resistance as its main manifestations in both children and adolescents (1). Various definitions of MetS in adolescents have been endorsed by national and international organizations, as well as the Balinese expert group (2). The following definitions have been frequently used in previous studies: Cook's definition, de Ferranti's definition, and the International Diabetes Federation (IDF) definition. Generally, MetS has an increasing prevalence among children and adolescents both globally and locally $(3,4)$. Based on different definitions, the overall prevalence of MetS in adolescents ranges from 1.2-9.8\% $(5,6)$ and from 4.5-8.4\% $(7,8)$, based on the modified Adult Treatment Panel III (ATP-III) and IDF definitions. Moreover, the prevalence of MetS was 9.8, 6.0, and 17.5\% in Iranian adolescents, based on the ATP-III, IDF, and de Ferranti's definitions, respectively (4).

Overall, the clinical significance of adolescent MetS in identifying future adverse outcomes is a matter of debate due to several reasons (9-11). First, identification of individuals with MetS is relatively more difficult in adolescents than adults due to indefinite recommendations for the diagnosis of MetS in this age group (12). Second, previous studies have suggested a marked instability in the diagnosis of MetS among adolescents $(13,14)$. Third, puberty stage has a significant effect on insulin resistance and the prevalence of MetS components (15). Finally, adulthood body mass index (BMI) has a confounding effect on the association of pediatric MetS with cardiovascular outcomes in early adulthood (16) (17). Moreover, it has been reported that specific combinations of metabolic phenotypes confer greater risks, especially among adolescents, and undermine the equal value of MetS components based on traditional definitions $(18,19)$.

The carotid intima-media thickness (CIMT) is a non-invasive, sensitive, and repeatable technique for the diagnosis and evaluation of subclinical atherosclerosis in asymptomatic individuals (20). Two meta-analyses showed that a high CIMT can predict the incidence of cardiovascular events in future adulthood $(21,22)$. Also, a stronger association was found between increased CIMT and mortality and cardiovascular events, including myocardial infarction and stroke in individuals younger than 50 years (23). Therefore, in this large population-based study, we aimed to examine the association between adolescent MetS based on different definitions and the incidence of high CIMT in adulthood during 18 years of follow-up. Also, the association of binary metabolic phenotypes with a high CIMT incidence was evaluated.

\section{Materials And Methods}




\section{Study population:}

This study was conducted based on the Tehran Lipid and Glucose Study (TLGS). We aimed to investigate the role of MetS and its phenotypes among children in predicting the incidence of a high CIMT. The TLGS is a large-scale community-based program for monitoring the trend of metabolic risk factors and developing a healthy lifestyle to reduce these risk factors (24). The baseline survey was a cross-sectional study conducted from 1999 to 2001. Survey 2 (2002-2005), survey 3 (2006-2008), survey 4 (20092011), survey 5 (2012-2015), and survey 6 (2016-2019) were prospective follow-up surveys; this cohort is still ongoing.

Of 4100 individuals under 18 years recruited in the baseline examination (first survey) of the TLGS, 2641 had follow-up data in the 5th or 6th survey of the TLGS. Phone calls were made to recruit subjects for the CIMT measurements. Of 2641 eligible individuals, 1186 did not refer to the medical center or consent to participate for the CIMT measurements. Of the remaining individuals, 496 were $<10$ years. Overall, 959 adolescents, aged 10-18 years, were included in this study. The median (IQ) follow-up duration was 18.2 (17.8-18.8) years. The CIMT was measured from February 2017 until October 2019.

The exclusion criteria were as follows: subjects with cancer $(n=1)$; chronic use of corticosteroids $(n=3)$; missing CIMT measurements $(n=5)$; being underweight $(n=53)$; pregnancy $(n=11)$; use of corticosteroids $(n=23)$; and having cancer $(n=1)$ at the end of follow-up. Finally, 862 participants remained in the study (Fig. 1). The baseline characteristics, except for age, sex, waist circumference (WC), and diastolic blood pressure (DBP), were not significantly different between the followed-up participants and those missed to the follow-up. The differences in age, sex, WC, and DBP were not clinically significant (supplementary Table 1).

\section{Measurements:}

Anthropometric measurements were obtained by qualified healthcare professionals, according to standard protocols (24); measurements were made while the subjects were minimally clothed without shoes. Weight was measured to the nearest $0.1 \mathrm{~kg}$, using a digital scale (Seca 707; range: 0.1-150 kg; Hanover, MD). A tape meter stadiometer was used to measure height while the subject was standing against a wall, with the shoulders in a normal alignment. WC was measured using an unstretched tape at the end of expiration at the narrowest level between the iliac crest and the lowest rib while the individual was in a standing position, and there was no pressure on the body surface. Height and WC were recorded with an accuracy of up to $0.1 \mathrm{~cm}$. BMI was also calculated as weight $(\mathrm{kg})$ divided by square of height $\left(\mathrm{m}^{2}\right)$.

Systolic blood pressure (SBP) and DBP were determined by a physician, using a standard mercury sphygmomanometer (calibrated by the Iranian Institute of Standards and Industrial Research). After the subject remained seated for 15 minutes, a blood pressure measurement was taken twice in at least a 30-second interval from the right brachial artery at the heart level. The mean values of measurements were considered as the individual's blood pressure. After 12 to 14 hours of fasting, a blood sample was taken between $7 \mathrm{am}$ and $9 \mathrm{am}$, based on the standard protocol. After centrifuging the collected blood sample, the serum was used for the measurement and analysis of fasting plasma glucose (FPG) and lipid concentrations on the day of blood collection at the TLGS Research Laboratory, using commercially available laboratory kits (Pars Azmoon Inc., Tehran, Iran), equipped with a Selectra 2 autoanalyzer.

The plasma glucose concentration was measured using an enzymatic colorimetric method with glucose oxidase. The inter- and intra-assay coefficients of variation (CVs) were both $2.2 \%$ for FPG. For the measurement of triglyceride (TG), we used an enzymatic colorimetric method with glycerol phosphate oxidase; the inter- and intra-assay CVs for TG were $0.6 \%$ and $1.6 \%$, respectively. Besides, total cholesterol (TC) was assessed with cholesterol esterase and cholesterol oxidase using the enzymatic colorimetric method. High-density lipoprotein-cholesterol (HDL-C) was measured after precipitation of apolipoprotein B, containing lipoproteins with a phosphotungstic acid. The inter- and intra-assay CVs for both TC and HDL-C were $0.5 \%$ and $2 \%$, respectively. When the TG concentrations were below $400 \mathrm{mg} / \mathrm{dL}$, the Friedewald formula was used to calculate the low-density lipoprotein-cholesterol (LDLC) level from the serum TC, TG, and HDL-C concentrations (25).

An ultrasound examination was performed in a linear 7.5-10 MHz transducer (Samsung Medison SonoAceR3 ultrasound machine). The subjects were examined in the supine position, with the neck extended and slightly rotated to the opposite side. The initial carotid scan was performed in the transverse plane throughout the artery to evaluate the subject's anatomy, locate atherosclerotic plaques (if there were any), and determine the site of maximal wall thickening in the near or far wall. Then, 
longitudinal scans of the artery were obtained from different angles. Measurements were done in plaque-free arterial segments, which also fulfilled the criteria of optimal B-mode imaging as described below.

Clear visualization of far-wall arterial interfaces with a completely anechoic luminal content was considered as the criterion for the optimal grey scale imaging of the carotid artery and saved for further measurements. We attempted to change the scan depth to have the arterial lumen at the center of image while setting the focal zone at the level of the arterial lumen. Generally, IMT is defined as a hypo-echoic band between the echogenic intimal and adventitial surfaces of the arterial wall. The distance between the leading edge of the first and second echogenic lines of the far walls of the distal segment of the common carotid artery was measured on both sides in three locations; the average value was considered as the final measurement of the side. The CIMT of carotid bulb and the internal carotid artery on both sides were sporadically measured in subjects that fulfilled the criteria of optimal technique and image. In the present study, we used the left common carotid artery (LCCA) measurements for defining a high CIMT and examined its association with MetS and metabolic phenotypes in children and adolescents.

The CIMT was measured by both radiologists in a subsample of 30 individuals ( $66.7 \%$ female) with the mean age and BMI of 41.7 \pm 10.7 years and $24.4 \pm 5.5 \mathrm{~kg} / \mathrm{m}^{2}$, respectively to examine the reliability agreement. The degree of agreement between the two radiologists regarding CIMT measurements was evaluated by calculating the interclass correlation coefficient (ICC). The ICC estimates and $95 \%$ confidence intervals (Cls) were calculated in SPSS version 20, using two-way mixed-effects model. The ICC results were reported as ICC $=0.79$ at $95 \% \mathrm{Cl}$ of $0.55-0.90$. Generally, the ICC ranges between 0 and 1 , where values between 0.75 and 0.9 indicate good reliability (26).

\section{Definitions:}

Overweight and obesity in childhood were defined based on the WHO age- and sex-specific BMI z-scores. In terms of childhood adiposity, obesity was classified as BMI-for-age $\geq 2$ SD; overweight was defined as 1 SD $\leq$ BMI-for-age < 2 SD; normal weight was defined as -2 SD $\leq$ BMI-for-age $<1$ SD, and underweight was defined as BMI-for-age $<-2$ SD for each gender.

\section{Definitions of MetS in adolescents:}

Table 1 presents the components and values for the three MetS definitions used in this study (Table 1). Cook et al. (27) defined MetS as having three or more of the following factors: $W C \geq 90$ th percentile for age and sex (according to the national reference curves); SBP or DBP $\geq 90 \%$ specific for gender, age, and height; TG $\geq 110 \mathrm{mg} / \mathrm{dL} ; \mathrm{HDL}-\mathrm{C} \leq 40 \mathrm{mg} / \mathrm{dL}$; and FPG $\geq 100 \mathrm{mg} / \mathrm{dL}$. On the other hand, in the definition proposed by de Ferranti (28), pediatric MetS was defined as having three or more of the following factors: waist $>75$ th percentile specific for age and sex; SBP or DBP $\geq 90 \%$ specific for gender, age, and height; $\mathrm{HDL}-\mathrm{C} \leq 50 \mathrm{mg} / \mathrm{dL}$ and/or FPG $\geq 100 \mathrm{mg} / \mathrm{dL}$. 
MetS Definitions and Their Components

\begin{tabular}{|c|c|c|c|c|}
\hline Definitions: & $\begin{array}{l}\text { Abdominal } \\
\text { obesity }\end{array}$ & Hypertension & Dyslipidemia & $\begin{array}{l}\text { Fasting } \\
\text { Glucose }\end{array}$ \\
\hline $\begin{array}{l}\text { Cook et al. } \\
3 \text { out of } 5^{\text {a }}\end{array}$ & $W C \geq 90$ th $^{b}$ & $\geq 90$ th & $\begin{array}{l}\mathrm{TG} \geq 110 \mathrm{mg} / \mathrm{dL}^{\mathrm{d}} \text { or } \mathrm{HDL}-\mathrm{C} \leq 40 \\
\mathrm{mg} / \mathrm{dL}^{\mathrm{e}}\end{array}$ & $\begin{array}{l}\mathrm{FPG} \geq 100 \\
\mathrm{mg} / \mathrm{dL}\end{array}$ \\
\hline $\begin{array}{l}\text { De Ferranti et al. } \\
\text { (28) } \\
3 \text { out of } 5^{\text {a }}\end{array}$ & WC $\geq 75$ th & $\geq 90$ th & $\begin{array}{l}\mathrm{TG} \geq 100 \mathrm{mg} / \mathrm{dL} \text { or } \mathrm{HDL}-\mathrm{C} \leq 50 \\
\mathrm{mg} / \mathrm{dL}\end{array}$ & $\begin{array}{l}\mathrm{FPG} \geq 100 \\
\mathrm{mg} / \mathrm{dL}\end{array}$ \\
\hline $\begin{array}{l}\text { IDF } \\
\text { Central obesity } \\
+2 \text { of } 4^{\mathrm{a}}\end{array}$ & WC $\geq 90$ th & $\begin{array}{l}\mathrm{DBP} \geq 130 \text { or } \mathrm{SBP} \geq 85 \mathrm{mmHg} \\
\text { or taking } \mathrm{AHD}\end{array}$ & $\begin{array}{l}\mathrm{TG} \geq 150 \mathrm{mg} / \mathrm{dL} \text { or } \mathrm{HDL}-\mathrm{C}<40 \mathrm{mg} / \mathrm{dL} \\
\text { or taking LLD }\end{array}$ & $\begin{array}{l}\mathrm{FPG} \geq 100 \\
\mathrm{mg} / \mathrm{dL}\end{array}$ \\
\hline \multicolumn{5}{|c|}{$\begin{array}{l}\text { AHD: antihypertensive drug; LLD: lipid lowering drug } \\
\text { a Number of criteria that must be fulfilled for diagnosing MetS. }\end{array}$} \\
\hline \multicolumn{5}{|c|}{$\begin{array}{l}\text { b Age- and sex-specific, recommended by NHANES III (National Health and Nutrition Examination Survey). } \\
\text { c Age-, sex-, and height-specific, recommended by NHBPEP (National High Blood Pressure Education Program). } \\
\text { d Age-specific, recommended by NCEP (National Cholesterol Education Program). }\end{array}$} \\
\hline
\end{tabular}

Moreover, according to the MetS definition by the IDF (29), central obesity is defined as WC $\geq 90$ th percentile plus any two of the following criteria: SBP $\geq 130 \mathrm{mmHg}$ and $\mathrm{DBP} \geq 85 \mathrm{mmHg}$; or treatment of previously diagnosed hypertension, $\mathrm{TG} \geq 150 \mathrm{mg} / \mathrm{dL}$, and HDL-C $<40 \mathrm{mg} / \mathrm{dL}$; or a specific treatment for a lipid abnormality and FPG $\geq 100 \mathrm{mg} / \mathrm{dL}$. It is important to note that the cut-off point for FPG was defined according to the recent recommendations by the American Diabetes Association (ADA) (30).

\section{Definitions of metabolic phenotypes:}

Cardiometabolic risk factors were defined based on the description by Cook et al. (27) in accordance with the National Cholesterol Education Program (Adult Treatment Panel III) definition, modified for age. At baseline, the adolescents were categorized into ten different metabolic phenotype groups as follows: high TG/low HDL-C; high TG/high WC; high WC/low HDL-C; high TG/hypertension (HTN); high TG/high FPG; HTN/low HDL-C; high FPG/low HDL-C; HTN/high FPG; high WC/HTN; and high WC/high FPG.

\section{Outcome definition:}

A high CIMT (subclinical atherosclerosis) was defined as CIMT of at least 95th percentile values specific for sex and age among 1450 Iranian children from the TLGS study.

\section{Statistical Analysis:}

All normally-distributed continuous variables were expressed as mean \pm standard deviation (SD). Otherwise, skewed-distributed continuous variables were shown as median and inter-quartile range (IQR) 25-75. Categorical variables of baseline characteristics were shown as frequency (percentages). Baseline characteristics of participants followed up and missed to follow-up were compared using independent sample t-test, Mann-Whitney $\mathrm{U}$ test, and chi-square test for normal, skewed, and categorical variables, respectively. The association between High CIMT ( $\geq 95 \%$ percentile) and different children's MetS definitions is investigated by calculating the multiple-adjusted Odds ratios (ORs) using the logistic regression analysis. The regarded association was evaluated in two adjusted models as follows; Model 1 is adjusted for age, sex, adulthood smoking and family history of CVD; model 2 is adjusted for age, sex, adulthood smoking, family history of CVD, and adulthood BMI. Odds ratios (ORs) of High CIMT ( $\geq 95 \%$ percentile) with $95 \%$ confidence intervals (Cls) were estimated for different children's MetS phenotypes using logistic regression in a 
similar way. All analyses were performed using SPSS software, version 20 (SPSS, Chicago, IL, USA) and two-tailed P< 0.05 were considered significant.

\section{Results}

In the current study, 862 children and adolescents (52.3\% male), with the mean age and BMI of $13.4 \pm 2.2$ years and $20.1 \pm 3.9$ $\mathrm{kg} / \mathrm{m}^{2}$, were included. The demographic and clinical characteristics of the participants who were successfully followed-up are shown in Table 2. The mean value of CIMT was $0.56 \pm 0.098 \mathrm{~mm}$, and the prevalence of high CIMT was $8.9 \%$ among adults. 
Table 2

Baseline characteristics of participants

\begin{tabular}{|c|c|c|}
\hline & Childhood (Baseline) & Adulthood \\
\hline Male (\%) & $451(52.3 \%)$ & - \\
\hline Age (y) & $13.42 \pm 2.16$ & $32.15 \pm 2.36$ \\
\hline Weight (kg) & $49.88 \pm 13.93$ & $76.51 \pm 16.96$ \\
\hline BMI $\left(\mathrm{kg} / \mathrm{m}^{2}\right)$ & $20.12 \pm 3.88$ & $26.77 \pm 4.75$ \\
\hline Normal weight, n(\%) & $638(75.1)$ & $316(37.5)$ \\
\hline Overweight, n(\%) & 152(17.9) & $358(42.5)$ \\
\hline Obese, n(\%) & $59(6.9)$ & $168(20.0)$ \\
\hline WC $(\mathrm{cm})$ & $68.81 \pm 10.02$ & $90.27 \pm 12.08$ \\
\hline Abdominal obesity, n(\%) & $129(15.2)$ & $415(49.1)$ \\
\hline $\mathrm{SBP}(\mathrm{mmHg})$ & $104.99 \pm 11.60$ & $107.78 \pm 12.49$ \\
\hline $\mathrm{DBP}(\mathrm{mmHg})$ & $70.46 \pm 9.17$ & $73.54 \pm 9.27$ \\
\hline HTN, n(\%) & $67(8.0)$ & $40(4.3)$ \\
\hline FPG (mg/dl) & $88.45 \pm 7.79$ & $89.22 \pm 10.85$ \\
\hline High FPG, n(\%) & $64(7.6)$ & $90(10.8)$ \\
\hline TG (mg/dl) & $98(74-135)$ & $103.5(73-153)$ \\
\hline High TG, n(\%) & $332(39.4)$ & $229(27.4)$ \\
\hline $\mathrm{HDL}-\mathrm{C}(\mathrm{mg} / \mathrm{dl})$ & $42.78 \pm 10.07$ & $46.43 \pm 11.08$ \\
\hline Low HDL_C, n(\%) & $374(44.4)$ & $374(44.8)$ \\
\hline Total Cholostrol (mg/dl) & $168.75 \pm 32.91$ & $176.62 \pm 34.64$ \\
\hline Family CVD & $43(5.1 \%)$ & $21(2.5 \%)$ \\
\hline MetS, n(\%) & & $101(12.1 \%)$ \\
\hline clMT (mm) & - & $0.56 \pm 0.098$ \\
\hline High IMT, n(\%) & - & $77(8.9 \%)$ \\
\hline \multicolumn{3}{|c|}{ Data are given as the mean \pm SD or median (IQ 25-75) unless otherwise indicated. } \\
\hline \multicolumn{3}{|c|}{$\begin{array}{l}\text { BMI, Body mass index; WC, Waist circumference; SBP, systolic blood pressure; DBP, diastolic blood pressure; FPG, Fasting } \\
\text { plasma glucose; TG, Triglycerides; HDL-C, high-density lipoprotein cholesterol; MetS, Metabolic syndrome; clMT, Intima-media } \\
\text { tickness of carotid artery. }\end{array}$} \\
\hline \multicolumn{3}{|c|}{$\begin{array}{l}\text { Hypertension was defined as SBP and/or DBP } \geq 90 \text { th percentile for sex, age and height according to Heart, Lung, and Blood } \\
\text { Institute standards. }\end{array}$} \\
\hline \multicolumn{3}{|c|}{ Metabolic syndrome in childhood and adulthood was definded by cook definition and JIS definition, respectively } \\
\hline
\end{tabular}

The prevalence of MetS among adolescents based on each definition was as follows: Cook's definition (12.1\%), de Ferranti's definition (27.2\%), NCEP's definition (8.7\%), and IDF's definition (10.0\%). There was an association between the presence of MetS and the incidence of a high CIMT based on Cook's definition ( $\mathrm{OR}=1.90,95 \% \mathrm{Cl}: 1.01-3.57, \mathrm{P}=0.046)$ and de Ferranti's definition $(\mathrm{OR}=1.74,95 \% \mathrm{Cl}: 1.04-2.90, \mathrm{P}=0.033)$ after adjusting for age, sex, family history of cardiovascular disease (CVD), and smoking. 
Nevertheless, after adjusting for adulthood BMI, there was no significant association between MetS and a high CIMT based on any of the definitions (Table 3).

Table 3

Multiple regression analysis for having High CIMT ( $\geq 95 \%$ percentile) among different children's MetS definitions

\begin{tabular}{|c|c|c|c|c|}
\hline & & Cook & De Ferranti & IDF \\
\hline \multicolumn{2}{|l|}{$\mathrm{N}(\%)$} & $101(12.1 \%)$ & $227(27.2 \%)$ & $86(10.0 \%)$ \\
\hline \multirow[t]{2}{*}{ Model 1} & OR & $1.90(1.01-3.57)$ & $1.74(1.04-2.90)$ & $1.35(0.55-2.98)$ \\
\hline & $P$-value & 0.046 & 0.033 & 0.510 \\
\hline \multirow[t]{2}{*}{ Model 2} & OR & $1.34(0.68-2.66)$ & $1.0(0.61-1.63)$ & $0.89(0.33-2.41)$ \\
\hline & $P$-value & 0.394 & 0.988 & 0.833 \\
\hline \multicolumn{5}{|c|}{ Model 1: adjusted for age, sex, family history CVD and smoking } \\
\hline \multicolumn{5}{|c|}{ Model 2: adjusted for age, sex, family history CVD, smoking and adulthood BMI } \\
\hline
\end{tabular}

Childhood metabolic phenotypes, such as high WC/HTN (OR = 2.87, 95\% Cl: 1.19-6.91,

$\mathrm{P}=0.018)$, high WC/low HDL-C $(\mathrm{OR}=2.98,95 \% \mathrm{Cl}: 1.58-5.63, \mathrm{P}=0.001)$, and high TG/high WC $(\mathrm{OR}=1.95,95 \% \mathrm{Cl}: 0.99-3.81, \mathrm{P}=$ 0.051), were significantly associated with an increased risk of a high CIMT in early adulthood (Table 4). After further adjustment for adulthood BMI, the only metabolic phenotype with a significant association with a high CIMT incidence was high WC/low HDL-C $(\mathrm{OR}=2.04,95 \% \mathrm{Cl}: 1.021-4.11, \mathrm{P}=0.044)$.

Table 4

Multiple regression analysis for having High CIMT ( $\geq 95 \%$ percentile) among different children's MetS phenotypes.

\begin{tabular}{|c|c|c|c|c|c|c|c|c|c|c|c|}
\hline & & $\begin{array}{l}\text { High } \\
\text { WC/ } \\
\text { FPG }\end{array}$ & $\begin{array}{l}\text { High } \\
\text { WČ/HTN }\end{array}$ & HTN/FPG & $\begin{array}{l}\text { High } \\
\text { FPG/low } \\
\text { HDL-C }\end{array}$ & $\begin{array}{l}\text { HTN/ } \\
\text { Low } \\
\text { HDL-C }\end{array}$ & $\begin{array}{l}\text { High } \\
\text { TG/ } \\
\text { FPG }\end{array}$ & $\begin{array}{l}\text { High } \\
\text { TG/ } \\
\text { HTN }\end{array}$ & $\begin{array}{l}\text { High } \\
\text { WC/low } \\
\text { HDL-C }\end{array}$ & $\begin{array}{l}\text { High } \\
\text { TG/high } \\
\text { WC }\end{array}$ & $\begin{array}{l}\text { High } \\
\text { TG/ } \\
\text { low } \\
\text { HDL-C }\end{array}$ \\
\hline \multicolumn{2}{|c|}{ Case (\%) } & $\begin{array}{l}12 \\
(1.4)\end{array}$ & $34(4.0)$ & $11(1.3)$ & $24(2.9)$ & $\begin{array}{l}58 \\
(6.9)\end{array}$ & $\begin{array}{l}26 \\
(3.1)\end{array}$ & $\begin{array}{l}73 \\
(8.6)\end{array}$ & 77 (9.1) & $83(9.7)$ & $\begin{array}{l}198 \\
(23.5)\end{array}$ \\
\hline \multirow{3}{*}{$\begin{array}{l}\text { Model } \\
1\end{array}$} & OR & 0.95 & 2.87 & 1.01 & 1.02 & 1.53 & 0.92 & 0.97 & 2.98 & 1.95 & 1.04 \\
\hline & & $\begin{array}{l}(0.12- \\
7.50)\end{array}$ & $\begin{array}{l}(1.19- \\
6.91)\end{array}$ & $\begin{array}{l}(0.125- \\
8.052)\end{array}$ & $\begin{array}{l}(0.23- \\
4.49)\end{array}$ & $\begin{array}{l}(0.66- \\
3.54)\end{array}$ & $\begin{array}{l}(0.21- \\
4.01)\end{array}$ & $\begin{array}{l}(0.40- \\
2.35)\end{array}$ & $\begin{array}{l}(1.58- \\
5.63)\end{array}$ & $\begin{array}{l}(0.99- \\
3.81)\end{array}$ & $\begin{array}{l}(0.58- \\
1.85)\end{array}$ \\
\hline & $\begin{array}{l}P \text { - } \\
\text { value }\end{array}$ & 0.962 & 0.018 & 0.998 & 0.971 & 0.312 & 0.913 & 0.96 & 0.001 & 0.051 & 0.883 \\
\hline \multirow{3}{*}{$\begin{array}{l}\text { Model } \\
2\end{array}$} & OR & .64 & 1.80 & 0.84 & 0.88 & 1.15 & 0.80 & 0.69 & 2.04 & 1.18 & 0.793 \\
\hline & & $\begin{array}{l}(0.08- \\
5.19)\end{array}$ & $\begin{array}{l}(0.69- \\
4.67)\end{array}$ & $\begin{array}{l}(0.10- \\
6.91)\end{array}$ & $\begin{array}{l}(0.19- \\
3.94)\end{array}$ & $\begin{array}{l}(0.48- \\
2.79)\end{array}$ & $\begin{array}{l}(0.18- \\
3.54)\end{array}$ & $\begin{array}{l}(0.27- \\
1.74)\end{array}$ & $\begin{array}{l}(1.021- \\
4.11)\end{array}$ & $\begin{array}{l}(0.55- \\
2.48)\end{array}$ & $\begin{array}{l}(0.432- \\
1.45)\end{array}$ \\
\hline & $\begin{array}{l}P \text { - } \\
\text { value }\end{array}$ & 0.679 & 0.225 & 0.878 & 0.869 & 0.743 & 0.769 & 0.440 & 0.044 & 0.665 & 0.454 \\
\hline \multicolumn{12}{|c|}{$\begin{array}{l}\text { BMI, Body mass index; WC, Waist circumference; BP, Blood pressure; FPG, Fasting plasma glucose; TG, Triglycerides; HDL-C, } \\
\text { high-density lipoprotein cholesterol; MetS, Metabolic syndrome; cIMT, Intima-media thickness of carotid artery; OR, Odds ratios } \\
(95 \% \mathrm{Cl}) \text {. }\end{array}$} \\
\hline \multicolumn{12}{|c|}{ Model 1: adjusted for age, sex, family history CVD and smoking } \\
\hline \multicolumn{12}{|c|}{ Model 2: adjusted for age, sex, family history CVD, smoking and adulthood BMI } \\
\hline
\end{tabular}

\section{Discussion}


This prospective cohort study with 18.2 years of follow-up showed that the presence of MetS during adolescence, based on Cook and de Ferranti's definitions, increased the risk of high a CIMT during adulthood. However, after adjusting for adulthood BMI, no significant association was found based on any of the MetS definitions. Moreover, adolescents with high WC/low HDL-C or high WC/HTN or high TG/high WC metabolic phenotypes had higher risks of a high CIMT. After adjusting for adulthood BMI, the high WC/low HDL-C metabolic phenotype was still significantly associated with an increased risk of adulthood high CIMT.

The importance of MetS during childhood and adolescence is a controversial issue. Several studies have suggested an association between pediatric MetS and the increased risk of MetS, type 2 diabetes, and subclinical atherosclerosis (31). On the other hand, similar predictive values have been reported for simpler screening tools, such as BMI, to identify adulthood MetS (32). Moreover, the confounding effect of adulthood BMI on the association between pediatric MetS and adulthood MetS reveals the insignificance of MetS during childhood and adolescence (11). Therefore, further research is needed on the importance of MetS during childhood and adolescence.

Different definitions of MetS have been proposed; three widely used definitions of pediatric MetS in observational studies are Cook, de Ferranti, and pediatric IDF definitions (12) (13). A previous study on the TLGS showed a positive association between metabolic phenotypes and the early adult MetS (33). Moreover, Koskinen et al. showed that MetS, based on several definitions (Cook, modified National Cholesterol Education Program (MetSNCEP75), and MetSPed), was associated with a high CIMT among adolescents $>11$ years (31). Consistently, we found that the presence of MetS based on Cook and de Ferranti's definitions increased the risk of a high CIMT incidence during adulthood. It is important to note that this association became insignificant after adjusting for adulthood BMI.

Previous studies have suggested the independent role of MetS components in children to predict cardiovascular and metabolic outcomes in adulthood. High TG and high WC have been shown to be associated with adulthood MetS $(11,34)$. Moreover, in the analysis of MetS components, different combinations of the components were found to predict the early adult MetS (11). Accordingly, a hypertriglyceridemic waist phenotype can be used simply to identify adolescents at a higher risk of metabolic abnormalities and CVD $(35,36)$. Zhao et al., in a cross-sectional study, showed that clustering of cardiometabolic risk factors predicted a high CIMT in childhood significantly better than MetS (AUC $=0.66$ vs. 0.54$)$ (37). Also, Koskinen et al., combining four cohort studies (31), reported that a high insulin level between the age of 11 and 16 years and high TG and low HDL-cholesterol levels between the age of 14 and 18 years were associated with a high CIMT. In this study, it was found that high WC/HTN, high WC/low HDL-C, and high TG/high WC metabolic phenotypes in adolescents were associated with the incidence of a high CIMT in future adulthood.

The substantial confounding effect of adulthood BMI on the association between adolescent MetS and adulthood high CIMT was found in the present study. After adjusting for adulthood BMI, all positive associations between the metabolic phenotypes and MetS became null. Also, previous studies have shown that individuals with a decreasing BMI trajectory from adolescence to adulthood (excess to normal weight) do not have an increased CIMT (38-40); highlighting the importance of tracking BMI from adolescents to adulthood. Considering the importance of final weight achieved in adulthood, irrespective of BMI status in adolescence, when we are faced with adolescents affected by MetS we can advise them to get to an appropriate BMI in future to prevent development of high CIMT in adult years.

An unexpected finding of the current study was the persistent positive association between the high WC/low HDL-C metabolic phenotype and the incidence of a high CIMT in adulthood, even after adjusting for adulthood BMI. Therefore, this phenotype can be used as a simpler alternative for MetS to predict early adulthood high CIMT. This is an interesting metabolic phenotype with genetic determinants, which can be investigated in future studies to discover possible conditions leading to this unhealthy metabolic status.

This study had several limitations. First, the serum insulin level was not measured to determine insulin resistance as a metabolic risk factor. Second, the participants were not divided into different age groups due to the low number of subjects in each age group. Finally, some possible confounders, such as puberty stage, physical activity, dietary habits, and socioeconomic status, were not considered. 
To the best of our knowledge, this is the first cohort study to explore the role of metabolic phenotypes among adolescents in predicting an increased CIMT in early adulthood. The prospective design and the duration of follow-up are the main strengths of this study. Also, national definitions and cut-off points were used in this study. Finally, data were obtained by trained technicians to reduce subjective errors, and no self-report measure was used.

In conclusion, the presence of MetS, based on Cook and de Ferranti's definitions, increased the risk of a high CIMT incidence in adulthood. Nevertheless, after adjusting for adulthood BMI, the association became insignificant. However, a specific binary combination of metabolic abnormalities (high WC/low HDL-c) had a positive association with a high CIMT, even after adjusting for adulthood BMl; this indicates the higher predictive value of this association. However, future studies with long-term follow-ups are required to clarify the relationship between metabolic phenotypes, especially high WC/low HDL-C, and the incidence of a high CIMT and other cardiovascular outcomes in adulthood.

\section{Figure Legends:}

Figure 1. Diagram showing the selection process of study participants

\section{Declarations}

Conflict of Interest: The authors declare that they have no potential conflicts of interest to disclose.

Financial Support: Not applicable.

Authors' Contributions: FH and ET: Study design; ET and RH: Literature review, data analysis, interpretation, and manuscript preparation; MM: statistical analysis; PD, AMM, and AAM: data collection; and MB, MV, FA, and FH: manuscript review, critical appraisal, and specialist consultation. All authors read and approved the manuscript.

Acknowledgments: We would like to acknowledge the staff and participants of the TLGS for their significant contribution to this study.

Ethical Approval and Consent to Participate: At the beginning of the study, all participants provided a written informed consent form. This study was approved by the Ethics Committee of the Research Institute for Endocrine Sciences and was conducted according to the principles of the Declaration of Helsinki.

Data Availability Statement: The data that support the findings of this study are available from the corresponding author upon reasonable request.

\section{References}

1. Steinberger J, Daniels SR, Eckel RH, Hayman L, Lustig RH, McCrindle B, et al. Progress and challenges in metabolic syndrome in children and adolescents: a scientific statement from the American Heart Association Atherosclerosis, Hypertension, and Obesity in the Young Committee of the Council on Cardiovascular Disease in the Young; Council on Cardiovascular Nursing; and Council on Nutrition, Physical Activity, and Metabolism. Circulation. 2009;119(4):628-47.

2. Ford ES, Li C. Defining the metabolic syndrome in children and adolescents: will the real definition please stand up? J Pediatr. 2008;152(2):160-4.

3. Al-Hamad D, Raman V. Metabolic syndrome in children and adolescents. Transl Pediatr. 2017;6(4):397-407.

4. Ostovar R, Kiani F, Sayehmiri F, Yasemi M, Mohsenzadeh Y, Mohsenzadeh Y. Prevalence of metabolic syndrome in Iran: A metaanalysis. Electron Physician. 2017;9(10):5402-18.

5. Lee AM, Gurka MJ, DeBoer MD. Trends in Metabolic Syndrome Severity and Lifestyle Factors Among Adolescents. Pediatrics. 2016;137(3):e20153177.

6. Messiah SE, Arheart KL, Luke B, Lipshultz SE, Miller TL. Relationship between body mass index and metabolic syndrome risk factors among US 8- to 14-year-olds, 1999 to 2002. J Pediatr. 2008;153(2):215-21. 
7. Walker SE, Gurka MJ, Oliver MN, Johns DW, DeBoer MD. Racial/ethnic discrepancies in the metabolic syndrome begin in childhood and persist after adjustment for environmental factors. Nutrition, metabolism, and cardiovascular diseases. NMCD. 2012;22(2):141-8.

8. Ford ES, Li C, Zhao G, Pearson WS, Mokdad AH. Prevalence of the metabolic syndrome among U.S. adolescents using the definition from the International Diabetes Federation. Diabetes Care. 2008;31(3):587-9.

9. Chen W, Srinivasan SR, Li S, Xu J, Berenson GS. Metabolic syndrome variables at low levels in childhood are beneficially associated with adulthood cardiovascular risk: the Bogalusa Heart Study. Diabetes Care. 2005;28(1):126-31.

10. Schubert CM, Sun SS, Burns TL, Morrison JA, Huang TT. Predictive ability of childhood metabolic components for adult metabolic syndrome and type 2 diabetes. J Pediatr. 2009;155(3):6.e1-7.

11. Hosseinpanah F, Asghari G, Barzin M, Ghareh S, Azizi F. Adolescence metabolic syndrome or adiposity and early adult metabolic syndrome. J Pediatr. 2013;163(6):1663-9.e1.

12. Mameli C, Zuccotti GV, Carnovale C, Galli E, Nannini P, Cervia D, et al. An update on the assessment and management of metabolic syndrome, a growing medical emergency in paediatric populations. Pharmacological research. 2017;119:99-117.

13. Asghari G, Eftekharzadeh A, Hosseinpanah F, Ghareh S, Mirmiran P, Azizi F. Instability of different adolescent metabolic syndrome definitions tracked into early adulthood metabolic syndrome: Tehran Lipid and Glucose Study (TLGS). Pediatr Diabetes. 2017;18(1):59-66.

14. Goodman E, Daniels SR, Meigs JB, Dolan LM. Instability in the diagnosis of metabolic syndrome in adolescents. Circulation. 2007;115(17):2316-22.

15. Reinehr T. Metabolic Syndrome in Children and Adolescents: a Critical Approach Considering the Interaction between Pubertal Stage and Insulin Resistance. Curr DiabRep. 2016;16(1):8.

16. 16. !!! INVALID CITATION !!! (11).

17. Tirosh A, Shai I, Afek A, Dubnov-Raz G, Ayalon N, Gordon B, et al. Adolescent BMI trajectory and risk of diabetes versus coronary disease. N Engl J Med. 2011;364(14):1315-25.

18. Goodman E, Dolan LM, Morrison JA, Daniels SR. Factor analysis of clustered cardiovascular risks in adolescence: obesity is the predominant correlate of risk among youth. Circulation. 2005;111(15):1970-7.

19. Conceição-Machado ME, Silva LR, Santana ML, Pinto EJ, Silva Rde C, Moraes LT, et al. Hypertriglyceridemic waist phenotype: association with metabolic abnormalities in adolescents. Jornal de pediatria. 2013;89(1):56-63.

20. Stein JH, Korcarz CE, Hurst RT, Lonn E, Kendall CB, Mohler ER, et al. Use of carotid ultrasound to identify subclinical vascular disease and evaluate cardiovascular disease risk: a consensus statement from the American Society of Echocardiography Carotid Intima-Media Thickness Task Force. Endorsed by the Society for Vascular Medicine. J Am Soc Echocardiogr. 2008;21(2):93-111. quiz 89-90.

21. Lorenz MW, Markus HS, Bots ML, Rosvall M, Sitzer M. Prediction of clinical cardiovascular events with carotid intima-media thickness: a systematic review and meta-analysis. Circulation. 2007;115(4):459-67.

22. van den Oord SC, Sijbrands EJ, ten Kate GL, van Klaveren D, van Domburg RT, van der Steen AF, et al. Carotid intima-media thickness for cardiovascular risk assessment: systematic review and meta-analysis. Atherosclerosis. 2013;228(1):1-11.

23. Lorenz MW, von Kegler S, Steinmetz H, Markus HS, Sitzer M. Carotid intima-media thickening indicates a higher vascular risk across a wide age range: prospective data from the Carotid Atherosclerosis Progression Study (CAPS). Stroke. 2006;37(1):8792.

24. Azizi F, Ghanbarian A, Momenan AA, Hadaegh F, Mirmiran P, Hedayati M, et al. Prevention of non-communicable disease in a population in nutrition transition: Tehran Lipid and Glucose Study phase II. Trials. 2009;10:5.

25. Friedewald WT, Levy RI, Fredrickson DS. Estimation of the concentration of low-density lipoprotein cholesterol in plasma, without use of the preparative ultracentrifuge. Clin Chem. 1972;18(6):499-502.

26. Koo TK, Li MY. A Guideline of Selecting and Reporting Intraclass Correlation Coefficients for Reliability Research. Journal of Chiropractic Medicine. 2016;15(2):155-63.

27. Cook S, Weitzman M, Auinger P, Nguyen M, Dietz WH. Prevalence of a metabolic syndrome phenotype in adolescents: findings from the third National Health and Nutrition Examination Survey, 1988-1994. Arch Pediatr Adolesc Med. 2003;157(8):821-7. 
28. de Ferranti SD, Gauvreau K, Ludwig DS, Neufeld EJ, Newburger JW, Rifai N. Prevalence of the metabolic syndrome in American adolescents: findings from the Third National Health and Nutrition Examination Survey. Circulation. 2004;110(16):2494-7.

29. Alberti KG, Zimmet P, Shaw J. The metabolic syndrome-a new worldwide definition. Lancet. 2005;366(9491):1059-62.

30. Genuth S, Alberti KG, Bennett P, Buse J, Defronzo R, Kahn R, et al. Follow-up report on the diagnosis of diabetes mellitus. Diabetes Care. 2003;26(11):3160-7.

31. Koskinen J, Magnussen CG, Sinaiko A, Woo J, Urbina E, Jacobs DR Jr, et al. Childhood Age and Associations Between Childhood Metabolic Syndrome and Adult Risk for Metabolic Syndrome, Type 2 Diabetes Mellitus and Carotid Intima Media Thickness: The International Childhood Cardiovascular Cohort Consortium. J Am Heart Assoc. 2017;6(8).

32. Magnussen CG, Koskinen J, Chen W, Thomson R, Schmidt MD, Srinivasan SR, et al. Pediatric metabolic syndrome predicts adulthood metabolic syndrome, subclinical atherosclerosis, and type 2 diabetes mellitus but is no better than body mass index alone: the Bogalusa Heart Study and the Cardiovascular Risk in Young Finns Study. Circulation. 2010;122(16):1604-11.

33. Hosseinpanah F, Salehpour M, Asghari G, Barzin M, Mirmiran P, Hatami H, et al. "Adolescent metabolic phenotypes and early adult metabolic syndrome: Tehran lipid and glucose study". Diabetes Res Clin Pract. 2015;109(2):287-92.

34. Juonala M, Magnussen CG, Berenson GS, Venn A, Burns TL, Sabin MA, et al. Childhood adiposity, adult adiposity, and cardiovascular risk factors. N Engl J Med. 2011;365(20):1876-85.

35. Arsenault BJ, Lemieux I, Despres JP, Wareham NJ, Kastelein JJ, Khaw KT, et al. The hypertriglyceridemic-waist phenotype and the risk of coronary artery disease: results from the EPIC-Norfolk prospective population study. Cmaj. 2010;182(13):1427-32.

36. Esmaillzadeh A, Mirmiran P, Azizi F. Clustering of metabolic abnormalities in adolescents with the hypertriglyceridemic waist phenotype. Am J Clin Nutr. 2006;83(1):36-46. quiz 183-4.

37. Zhao M, Caserta CA, Medeiros CCM, López-Bermejo A, Kollias A, Zhang Q, et al. Metabolic syndrome, clustering of cardiovascular risk factors and high carotid intima-media thickness in children and adolescents. J Hypertens. 2020;38(4):61824.

38. Su TC, Liao CC, Chien KL, Hsu SH, Sung FC. An overweight or obese status in childhood predicts subclinical atherosclerosis and prehypertension/hypertension in young adults. J Atheroscler Thromb. 2014;21(11):1170-82.

39. Yan Y, Liu J, Wang L, Hou D, Zhao X, Cheng H, et al. Independent influences of excessive body weight and elevated blood pressure from childhood on left ventricular geometric remodeling in adulthood. Int J Cardiol. 2017;243:492-6.

40. Juonala M, Viikari JS, Kähönen M, Taittonen L, Laitinen T, Hutri-Kähönen N, et al. Life-time risk factors and progression of carotid atherosclerosis in young adults: the Cardiovascular Risk in Young Finns study. Eur Heart J. 2010;31(14):1745-51.

\section{Figures}




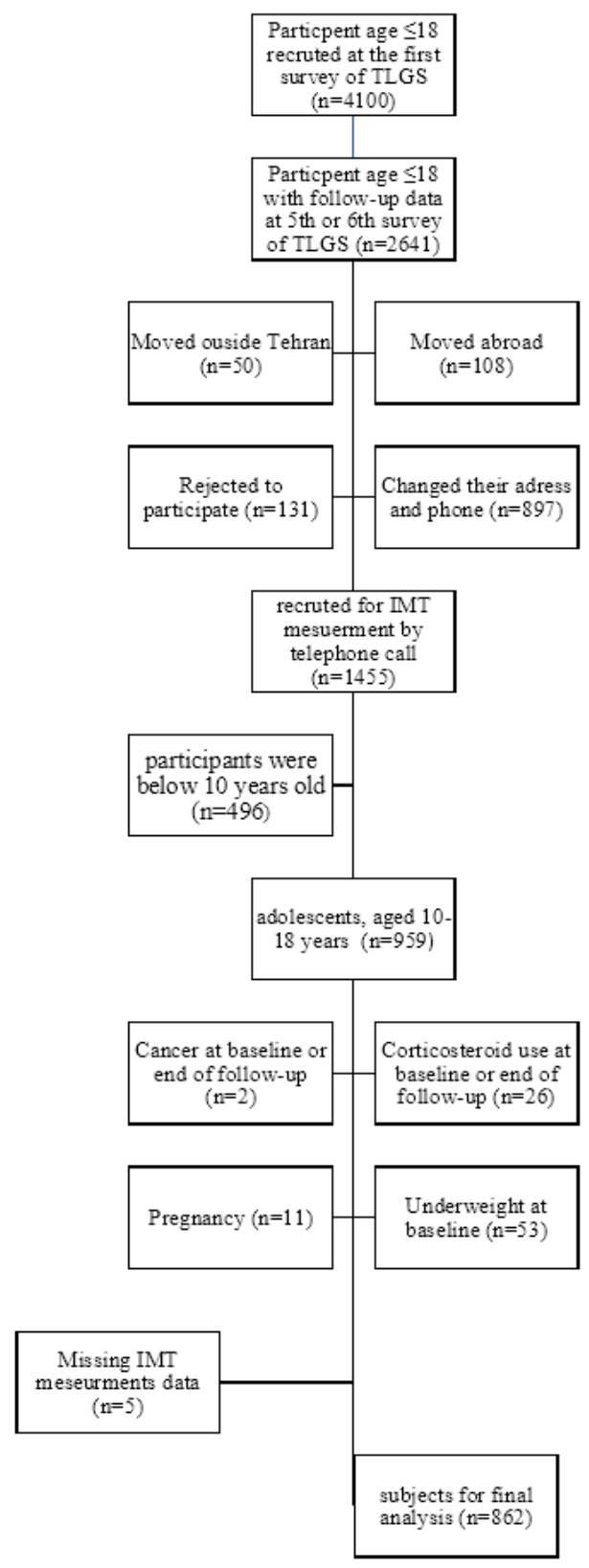

\section{Figure 1}

Diagram showing the selection process of study participants

\section{Supplementary Files}

This is a list of supplementary files associated with this preprint. Click to download.

- SupplemantoryTable1.docx 